\title{
New criteria for assessing low wind environment at pedestrian level in Hong Kong
}

Du, Yaxing; Mak, Cheuk Ming; Kwok, Kenny; Tse, Kam-Tim; Lee, Tsz-cheung; Ai, Zhengtao; Liu, Jianlin; Niu, Jianlei

\section{Published in:}

Building and Environment

Link to article, DOI:

10.1016/j.buildenv.2017.06.036

Publication date:

2017

Document Version

Peer reviewed version

Link back to DTU Orbit

Citation (APA):

Du, Y., Mak, C. M., Kwok, K., Tse, K-T., Lee, T., Ai, Z., Liu, J., \& Niu, J. (2017). New criteria for assessing low wind environment at pedestrian level in Hong Kong. Building and Environment, 123, 23-36.

https://doi.org/10.1016/j.buildenv.2017.06.036

\section{General rights}

Copyright and moral rights for the publications made accessible in the public portal are retained by the authors and/or other copyright owners and it is a condition of accessing publications that users recognise and abide by the legal requirements associated with these rights.

- Users may download and print one copy of any publication from the public portal for the purpose of private study or research.

- You may not further distribute the material or use it for any profit-making activity or commercial gain

- You may freely distribute the URL identifying the publication in the public portal 
Du, Y., Mak, C. M., Kwok, K., Tse, K-T., Lee, T., Ai, Z., Liu, J., Niu, J. (2017). New criteria for assessing low wind environment at pedestrian level in Hong Kong. Building and Environment, 123, 23-36. DOI:

10.1016/j.buildenv.2017.06.036

\section{New criteria for assessing low wind environment at pedestrian level in Hong Kong}

Yaxing Dü, Cheuk Ming Mak ${ }^{\mathrm{a} *}$, Kenny Kwok ${ }^{\mathrm{b}}, \mathrm{Kam}^{\mathrm{a}}$-Tim Tse ${ }^{\mathrm{c}}$, Tsz-cheung Lee ${ }^{\mathrm{d}}$, Zhengtao Ai ${ }^{\mathrm{e}}$, Jianlin Liu ${ }^{\mathrm{a}}$, Jianlei Niu ${ }^{\mathrm{f}}$

${ }^{a}$ Department of Building Services Engineering, The Hong Kong Polytechnic University, Hung Hom, Kowloon, Hong Kong

${ }^{b}$ Institute for Infrastructure Engineering, University of Western Sydney, Penrith, NSW, Australia

${ }^{c}$ Department of Civil and Environmental Engineering, The Hong Kong University of Science and Technology, Clear Water Bay, Kowloon, Hong Kong

${ }^{d}$ Hong Kong Observatory, Hong Kong

${ }^{e}$ International Center for Indoor Environment and Energy, Department of Civil Engineering, Technical University of Denmark, Denmark

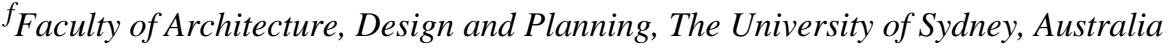

*Corresponding author email: cheuk-ming.mak@polyu.edu.hk

\section{Abstract}

The choice of proper wind comfort criterion is considered to be crucial to reliable assessment of pedestrian level wind comfort. This paper aims to propose a wind comfort criterion that can be applied to Hong Kong, in which the wind comfort is seriously deteriorated by the moderated airflow, particularly in the hot and humid summer. By thoroughly reviewing and comparing exiting wind comfort criteria, the parameters in Lawson (1978) criterion are adopted for acceptable, tolerable and intolerable category and the parameters in NEN8100 (2006) criterion are adopted for danger category in the proposed criteria. Besides, a low wind parameter suggested by AVA scheme (2005) is adopted for unfavourable category in summer criterion. The adopted parameters provide scientific foundations and they are carefully chosen to adapt the weak wind conditions. The prominent feature of the criteria is proposed seasonally (summer and winter, respectively) and the overall mean wind velocity ratio $(O M V R)$ is used as threshold wind velocity parameter. The wind tunnel tests of Hong Kong Polytechnic University (HKPolyU) campus model were used as a case study. The results show that the 
proposed criteria can reasonably represent the weak wind condition and provide suitable assessments of the wind comfort in Hong Kong. Moreover, the findings in this study provide scientific basis for future policy-making and the proposed criteria can also help city planners to improve the pedestrian level wind comfort.

Keywords: Wind comfort criteria; Pedestrian level wind comfort; Threshold mean wind velocity; Exceedance probability

\section{Introduction}

The wind flow at pedestrian level plays an important role in people's daily life, in the aspects of thermal comfort [1-6], city ventilation [7-9], pollutants dispersion [10-13] and public safety [14-16]. In recent years, the pedestrian level wind comfort has received lots of attentions since the successful achievement of the acceptable wind environment is seriously compromised by the dense and tall buildings in the urban areas [2, 17-22]. Under the rapid urbanization in the last few decades, there are many bulky high-rise buildings and narrow streets in Hong Kong, which can be seen from the photo in Fig.1. The high density of high-rise building blocks lower the permeability of the wind flow, which results in stagnant air at pedestrian level and causes lots of problems in Hong Kong, especially in hot and humid summer [5, 8, 21-24]. Recent studies also indicated that, against the background of global climate change and local urbanization, there is a rising trend in average temperature in Hong Kong and the hot period has become significantly longer over the last century [25]. Future projections also suggested that the warming trend will continue in the 21st century with a significant increase in extreme high temperature events [26]. Therefore, it is very important and necessary to assess the pedestrian level wind comfort and maintain an acceptable wind environment from both urban planning and public health perspectives.

In order to assess the pedestrian wind comfort, the meteorological data, aerodynamic information and the wind comfort criterion should be combined. The meteorological data are usually available 
from the local weather stations and the aerodynamic information can be acquired from the wind tunnel test or the Computational Fluid Dynamics (CFD) simulation [6, 10, 11, 14, 17, 22, 27, 28]. The choice of the wind comfort criterion is a crucial part in the assessment procedure, because lots of studies have proven that different criterion lead to different assessment results [15, 29-33]. In the past, a wide range of wind comfort criteria were proposed, particularly in the works of Isyumov and Davenport [34], Gandemer [35], Lawson [36] , Hunt et al. [37], Melbourne [31], Murakami et al. [38], Soligo [39], Durgin [40], and NEN 8100 [41]. Meanwhile, different wind comfort criteria were adopted in the building consultant institutes as well. Most of these criteria are based on the definitions of the threshold wind velocity and the maximum allowed exceedance probability. In addition, these wind comfort criteria categorised the principles according to various activities, like sitting, strolling, and walking. Apart from the above wind comfort criteria, $\mathrm{Bu}$ et al. [42] proposed two new criteria to evaluate the local wind environment based on the local air rate and the local kinetic energy. The outputs of the new criteria were presented in the form of cumulative distribution function, which can be used for reliability analysis of inadequate ventilation and thermal comfort.

There are noticeable differences among these wind comfort criteria that have been identified by previous studies [15, 30-33, 43]. Melbourne [31] concluded that the earlier published wind comfort criteria were quite different from each other owing to their independent developments. However, Ratcliff and Peterka [32] and Ohba et al. [43] both indicated that Melbourne's criterion was more restrictive than the other wind comfort criteria. Bottema [15] and Koss [30] both conducted overview of the existing wind comfort criteria in great details. Moreover, Koss [30] divided the wind comfort criteria into two groups based on the conceptual design of the different criteria: using the hourly mean wind velocity or the gust wind velocity as the threshold parameter to assess the wind comfort. Furthermore, Sanz-Andres and Cuerva [33] established the “iso-criteria lines” and compared several wind comfort criteria based on the two-dimensional display of these lines so that the differences 
between different criteria were distinguished. All in all, the aforementioned comparisons both suggest that the proper choice of the wind comfort criterion is very important for assessing wind environment.

It should be mentioned that the existing wind comfort criteria are mostly aimed at dealing with strong wind conditions, which means that pedestrian discomfort occurs when wind becomes so strong and happens so frequently. The existing wind comfort criteria cannot fully represent the weak wind condition. However, the mean wind velocity recorded in the urban area has decreased by more than 40\% due to the high-rises urban development in Hong Kong in the last few decades [44, 45], resulting in a relatively a low wind environment at pedestrian level in some densely populated areas. The Hong Kong Government has established the technical methodology and guidelines of Air Ventilation Assessment (AVA) system for enhancing the air movement at pedestrian level [9], but the scheme does not establish a criterion or recommended minimum threshold for assessing pedestrian wind comfort specifically. Therefore, to mitigate the negative impacts of urbanization, there is an urgent need to identify of an objective wind comfort criterion for assessing the wind environment in the places like Hong Kong. In addition, wind also plays an important role in heat and humidity dispersion, which is an essential contribution to the thermal comfort. This is especially important for the subtropical and tropical climates that have hot, humid summer and temperate, mild winter [1, 3, 4, 23].

The objective of the study is to propose new wind comfort criteria for the densely-built subtropical urban areas, which aims for the low wind environment. The HKPolyU campus model is used as the case study to illustrate the new wind comfort criteria. Firstly, the wind tunnel tests were carried out to obtain the aerodynamic information at pedestrian level of the HKPolyU campus. The wind comfort of the campus is then assessed by combining the meteorological statistics of the campus, the measurement data and the proposed criteria. For the purpose of comparison, the pedestrian level wind environment at the HKPolyU campus is also assessed by using the NEN 8100 [41] to demonstrate the prominent advantages of the proposed criteria for the low wind environment. Overall, the proposed criteria will 
provide a better evaluation for the low wind environment than the other criteria and it can also help the policy makers and city planners to better precinct planning.

This paper is organised in the following orders: after the introduction in Section1, a detailed overview of the known "complete” wind comfort criteria is presented in Section 2. Section 3 describes the methodology for the proposed criteria, and Section 4 discusses the application of the proposed criteria by applying the data obtained from wind tunnel tests. Finally, Section 5 concludes the paper.

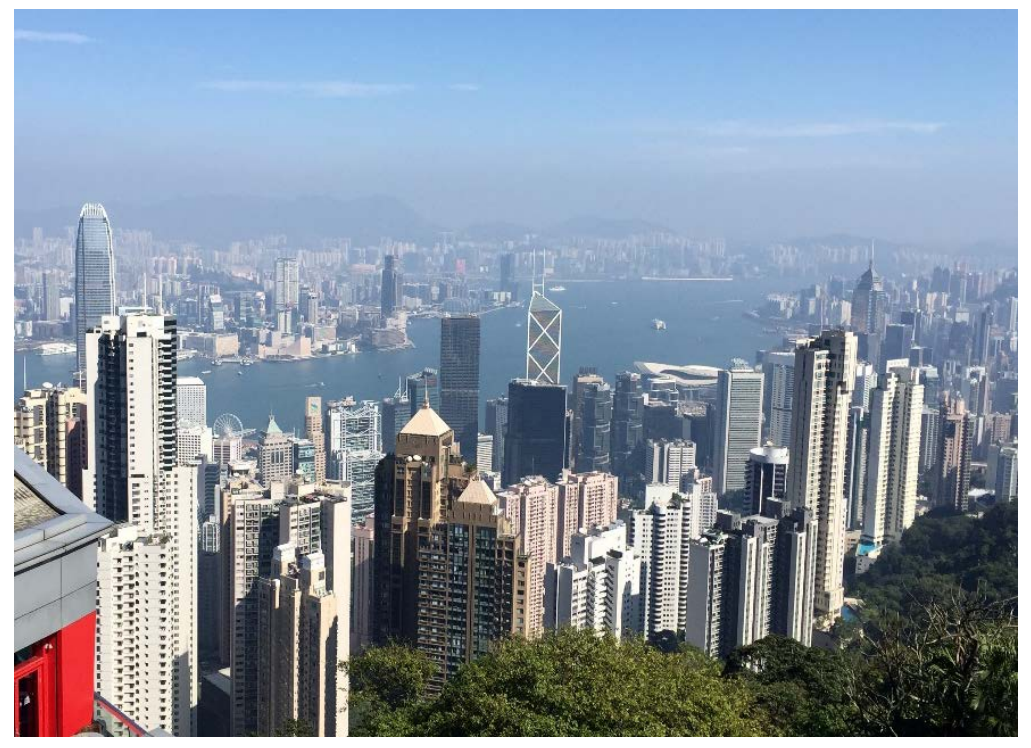

Fig.1 Overlook of Hong Kong from the Victoria Peak at daytime.

\section{Overview of the wind comfort criteria}

\subsection{Isyumov \&Davenport (1975) criterion [34] and Lawson (1978) criterion [36]}

The wind comfort criteria proposed by Isyumov \&Davenport and Lawson \& Penwarden are presented together in this section, because of the similarities of these two wind comfort criteria. These two wind comfort criteria both use mean wind velocity as the threshold parameter and the Beaufort scale to distinguish wind force on pedestrians. Besides, the exceedance probability of these two wind comfort criteria are the same in the criteria for different activities. However, the criterion by Isyumov \& Davenport is a Beaufort level higher than the criterion by Lawson while the value of the exceedance probability by Isyumov \&Davenport is smaller than that by Lawson. In addition, the descriptions to 
different pedestrian activities by these two wind comfort criteria have small differences. These two wind comfort criteria are summarized in Table 1.

Table 1. The wind comfort criteria by Isyumov \& Davenport (1975) and Lawson (1978)

\begin{tabular}{|c|c|c|c|c|c|}
\hline \multicolumn{3}{|c|}{ Isyumov \&Davenport } & \multicolumn{3}{|l|}{ Lawson } \\
\hline $\begin{array}{l}\text { Threshold value } \\
\text { (Beaufort scale) }\end{array}$ & $\begin{array}{l}\text { Exceedance } \\
\text { Probability }\end{array}$ & $\begin{array}{l}\text { Descriptions in } \\
\text { Reference[34] }\end{array}$ & $\begin{array}{l}\text { Threshold value } \\
\text { (Beaufort scale) }\end{array}$ & $\begin{array}{l}\text { Exceedance } \\
\text { Probability }\end{array}$ & $\begin{array}{l}\text { Descriptions in } \\
\text { Reference[36] }\end{array}$ \\
\hline 3 & 1.5\% (1/week) & $\begin{array}{l}\text { "Sitting, long } \\
\text { exposure" }\end{array}$ & 2 & $2 \%$ & $\begin{array}{l}\text { "Tolerable for covered } \\
\text { area" }\end{array}$ \\
\hline 4 & $1.5 \%$ (1/week) & $\begin{array}{l}\text { "Sitting, short } \\
\text { exposure" }\end{array}$ & 3 & $2 \%$ & $\begin{array}{l}\text { "Tolerable for entrance } \\
\text { doors and stand around" }\end{array}$ \\
\hline 5 & $1.5 \%$ (1/week) & $\begin{array}{l}\text { "Strolling, } \\
\text { Skating" }\end{array}$ & 4 & $2 \%$ & $\begin{array}{l}\text { "Tolerable for pedestrian } \\
\text { walk-through and around } \\
\text { buildings" }\end{array}$ \\
\hline 6 & $1.5 \%$ (1/week) & "Walking fast" & 5 & $2 \%$ & $\begin{array}{l}\text { “Tolerable for roads, car } \\
\text { parks" }\end{array}$ \\
\hline 8 & $0.01 \%$ (1/year) & "Dangerous" & 6 & $2 \%$ & "Unacceptable" \\
\hline
\end{tabular}

2.2 Hunt (1976) criterion [37]

Hunt et al. [37] proposed the wind comfort criterion based on the controlled wind tunnel test, which were conducted to investigate how wind velocity and turbulence intensity affect human's abilities to perform simple tasks. The wind comfort criterion used the equivalent steady wind velocity $u_{s}$ as the evaluation parameters, which defined as the following equations in his study:

$$
u_{s} \cong \bar{u}\left[1+3 \times \sigma_{u}\right]
$$

where, $\bar{u}$ is the mean wind velocity, $\sigma_{u}$ is the turbulence intensity.

In order to describe the wind environment at pedestrian level, the wind comfort criterion was proposed according to different pedestrian activities. For wind comfort that is suitable for pedestrian linger, sit down, shop and walk around:

$$
u_{s} \cong \bar{u}\left[1+3 \times \sigma_{u}\right]<9 \mathrm{~m} / \mathrm{s}
$$

The exceedance probability for wind comfort condition is $90 \%$. Besides, the study pointed out that $u_{s}$ should be less than $6 \mathrm{~m} / \mathrm{s}$ for the pedestrian who felt discomfort for wind but the exceedance probability is still 90\%. For wind safety:

$$
u_{s} \cong \bar{u}\left[1+3 \times \sigma_{u}\right]<13 \mathrm{~m} / \mathrm{s}
$$


The exceedance probability for wind comfort condition is $1 \%$. It should be noted that the wind comfort criterion proposed by Hunt et al. is very concise and aimed for application without elaborate statistical analysis. However, this wind comfort criterion aims at the general wind environment of London and there is a lack of confidence survey. Therefore, measurements around the buildings should be carried out and confidence surveys about pedestrian reactions are needed.

\subsection{Melbourne (1978) criterion [31]}

The wind comfort criterion by Melbourne was developed based on two levels of wind velocity: 1) the wind velocity that could be generally accepted by the pedestrian in a city; 2) the wind velocity that is high enough to blow pedestrian over, which is demonstrated in Table 2. This wind comfort criterion uses the peak gust wind velocity $\hat{u}$ as the threshold parameter, which is defined as follows:

$$
\hat{u}=\bar{u}+3.5 \sigma_{u}
$$

where, $\bar{u}$ is the mean wind velocity and $\sigma_{u}$ is the turbulence intensity.

Table 2. The wind comfort criterion by Melbourne (1978)

\begin{tabular}{lcc}
\hline Category & Peak Gust Wind velocity $(\hat{u})$ & Exceedance Probability \\
\hline Long exposure & $<10 \mathrm{~m} / \mathrm{s}$ & $0.002 \%(2 \mathrm{~h} /$ year $)$ \\
Short exposure & $<13 \mathrm{~m} / \mathrm{s}$ & $0.002 \%(2 \mathrm{~h} /$ year $)$ \\
Walking & $<16 \mathrm{~m} / \mathrm{s}$ & $0.002 \%(2 \mathrm{~h} /$ year $)$ \\
Danger & $>23 \mathrm{~m} / \mathrm{s}$ & $0.002 \%(2 \mathrm{~h} /$ year $)$ \\
\hline
\end{tabular}

It is obvious that the threshold value for the wind velocity is large, but the exceedance probability is very small, which renders this wind comfort criteria strictly for evaluating the strong wind condition.

\subsection{Soligo et al. (1998) criterion [46]}

Soligo et al. proposed the wind comfort criteria based on the previous wind comfort criteria (Isyumov \&Davenport (1975), Lawson (1978), Hunt et al. (1976), Melbourne (1978) etc. It divides the pedestrian wind comfort into five categories and employs mean wind velocity as the threshold velocity parameter. The prominent characteristic of this wind comfort criteria is that the exceedance probability for all kinds of activities is $20 \%$, which corresponds to the fact that American Society of 
Heating, Refrigeration and Air Conditioning Engineers (ASHRAE) has used 80\% for indoor comfort application. The detailed description of this wind comfort criteria is presented in Table 3.

Table 3. The wind comfort criteria by Soligo et al. (1998)

\begin{tabular}{lcc}
\hline Category & Mean Wind velocity & Exceedance Probability \\
\hline Sitting & $<2.5 \mathrm{~m} / \mathrm{s}$ & $20 \%$ \\
Standing & $2.5 \mathrm{~m} / \mathrm{s}-3.89 \mathrm{~m} / \mathrm{s}$ & $20 \%$ \\
Walking & $3.89 \mathrm{~m} / \mathrm{s}-5 \mathrm{~m} / \mathrm{s}$ & $20 \%$ \\
Uncomfortable & $>5 \mathrm{~m} / \mathrm{s}$ & $20 \%$ \\
Severe & $\geq 14.44 \mathrm{~m} / \mathrm{s}$ & $20 \%$ \\
\hline
\end{tabular}

The wind comfort criterion is designed to be simple and easily to be understood by the end users, namely the developers, the architects, the city planners, as well as the general public. Besides, the choice of $80 \%$ for the exceedance probability is flexible because it can be changed slightly according to the local experience. In general, this wind comfort criterion aims to be adaptable to various meteorological statistics and different planning objectives. However, this adaption may lead to different results even for one project.

\subsection{Dutch Wind Nuisance Standard NEN 8100 (2006) [41]}

The wind comfort criterion proposed by the Netherlands Normalised Institute NEN adopted mean wind velocity as the threshold wind velocity parameter. In the NEN 8100 (2006) wind comfort criterion, the mean wind velocity of $5 \mathrm{~m} / \mathrm{s}$ is set as the threshold wind velocity for all levels of pedestrian activities and the mean wind velocity of $15 \mathrm{~m} / \mathrm{s}$ is used for the threshold wind velocity of danger. The probability that exceeds $5 \mathrm{~m} / \mathrm{s}$ is used as the standard for evaluate different wind comfort level. It is indicated in this wind comfort criterion that the larger value of the exceedance probability, the less wind comfortable for pedestrian activities. Besides, five levels of wind comfort are defined in the wind comfort criterion, which are labelled as A-E. Furthermore, the adjective words of "poor", "moderate" and "good" are used to evaluate different pedestrian activities (traversing, strolling and sitting). The detailed description of NEN 8100 is shown in Table 4.

Table 4. The wind comfort criteria by NEN 8100 (2006) 


\begin{tabular}{ccc|lll}
\hline Wind Comfort & \multicolumn{5}{l}{} \\
\hline Grade & $\begin{array}{c}\text { Mean Wind } \\
\text { velocity }\end{array}$ & $\begin{array}{c}\text { Threshold Probability } \\
\text { Exceedance }\end{array}$ & Activity Descriptions & \\
\cline { 3 - 5 } & $5 \mathrm{~m} / \mathrm{s}$ & $2.5 \%$ & Sitting & Strolling & Traversing \\
\hline $\mathrm{A}$ & $5 \mathrm{~m} / \mathrm{s}$ & $5 \%$ & Moderate & Good & Good \\
$\mathrm{B}$ & $5 \mathrm{~m} / \mathrm{s}$ & $10 \%$ & Poor & Moderate & Good \\
$\mathrm{C}$ & $5 \mathrm{~m} / \mathrm{s}$ & $20 \%$ & Poor & Poor & Moderate \\
$\mathrm{D}$ & $5 \mathrm{~m} / \mathrm{s}$ & $>20 \%$ & Poor & Poor & Poor \\
E & & & & & \\
\hline Wind Danger & $15 \mathrm{~m} / \mathrm{s}$ & $0.05 \%-0.3 \%$ & & \\
\hline Limited risk & $15 \mathrm{~m} / \mathrm{s}$ & $>0.3 \%$ & & & \\
Dangerous & &
\end{tabular}

\subsection{Comparison between different wind comfort criteria}

\subsubsection{Categorize the activity descriptions}

The descriptions of the relevant activities in different wind comfort criteria are not always consistent. For the purpose of comparison, five categories used in reference [29] are adopted here, which are "sitting long, sitting short, strolling, walking fast and danger". The categorizations for each wind comfort criterion mentioned above are outlined in Table 5. It should be noted that this categorization is not suitable for the wind comfort criterion by Hunt, because the threshold wind velocity and exceedance probability are defined the same for all kinds of pedestrian activities.

Table 5. The categorizations of the activity description for different wind comfort criteria [31, 34, $36,41,46]$

\begin{tabular}{|c|c|c|}
\hline Category & Referred criteria & Description of activities \\
\hline \multirow[t]{5}{*}{ Sitting Long } & Isyumov \&Davenport (1975) & "Acceptable for sitting, long exposure" \\
\hline & Lawson (1978) & "Tolerable for covered area" \\
\hline & Melbourne (1978) & “Long exposure” \\
\hline & Soligo (1998) & “Sitting” \\
\hline & NEN 8100 (2006) & "Quality class A" \\
\hline \multirow[t]{5}{*}{ Sitting Short } & Isyumov \&Davenport (1972) & "Acceptable for sitting, short exposure" \\
\hline & Lawson (1978) & "Tolerable for entrance doors and stand around" \\
\hline & Melbourne (1978) & "Short exposure" \\
\hline & Soligo (1998) & “Standing” \\
\hline & NEN 8100 (2006) & "Quality class B” \\
\hline \multirow[t]{5}{*}{ Strolling } & Isyumov \&Davenport (1972) & “Acceptable for strolling, skating" \\
\hline & Lawson (1978) & "Tolerable for pedestrian walk-through and around buildings" \\
\hline & Melbourne (1978) & "Walking”" \\
\hline & Soligo (1998) & "Walking" \\
\hline & NEN 8100 (2006) & "Quality class C" \\
\hline \multirow[t]{4}{*}{ Walking Fast } & Isyumov \&Davenport (1972) & "Acceptable for brisk walking” \\
\hline & Lawson (1978) & "Tolerable for roads, car parks" \\
\hline & Soligo (1998) & “Uncomfortable" \\
\hline & NEN 8100 (2006) & “Quality class D” \\
\hline \multirow[t]{2}{*}{ Danger } & Isyumov \&Davenport (1972) & "Dangerous" \\
\hline & Melbourne (1978) & “Danger" \\
\hline
\end{tabular}




\subsubsection{Conversion of the threshold wind velocity parameter}

In order to compare the different wind comfort criteria, the turbulence intensity of $16 \%$ for the pedestrian level is adopted in this paper that corresponds with the Hong Kong Wind Code 2004 [47]. Thus, the equivalent steady wind velocity $u_{s}$ used in the wind comfort criteria by Hunt and the peak gust wind velocity $\hat{u}$ used by Melbourne can be converted to the mean wind velocity. Besides, the threshold wind velocities used in Isyumov \&Davenport (1975) and Lawson (1978) are in Beaufort scale. However, the corresponding wind velocity in $\mathrm{m} / \mathrm{s}$ scale has an interval of values for one particular Beaufort value. In order to translate the Beaufort scale into m/s unit, the bold values (mean values of the range) in Table 6 is employed. It should be noted that the translation is adopted from Isyumov \& Davenport (1975) [34] and also consistent with reference [29].

Table 6. Translation from the Beaufort scale to m/s unit [29,34]

\begin{tabular}{cccl}
\hline Wind Force (Bft) & Wind velocity Range $(\mathrm{m} / \mathrm{s})$ & Value used in this paper & Remark \\
2 & $1.3-2.7$ & $\mathbf{1 . 8}$ & Light breeze \\
3 & $2.7-4.4$ & $\mathbf{3 . 6}$ & Gentle breeze \\
4 & $4.4-6.7$ & $\mathbf{5 . 3}$ & Moderate breeze \\
5 & $6.7-8.9$ & $\mathbf{7 . 6}$ & Fresh Breeze \\
6 & $8.4-11.1$ & $\mathbf{9 . 8}$ & Strong breeze \\
7 & $11.1-13.8$ & $\mathbf{1 2 . 4}$ & Moderate Gale \\
8 & $13.8-16.9$ & $\mathbf{1 5 . 1}$ & Gale \\
\hline
\end{tabular}

\subsubsection{Comparison between different wind comfort criteria}

Refer to method that had been used in the previous studies [30, 32, 33], the comparison of different wind comfort criteria is presented in a two-dimensional geometrical plane in Fig. 2: the horizontal coordinates represents mean wind velocity and the vertical coordinates represents the exceedance percentage for its corresponding wind velocity. Different colours are used to distinguish the threshold value for the wind comfort criteria. The red curve stands for the annual wind climate of Hong Kong at pedestrian level (obtained from King's Park Meteorological Station 1993-2015) and the black curve is the typical wind climate used by Ratcliff and Peterka (1990) [32]. The blue line area represents the 
pedestrian level wind environment that occurs in Hong Kong. It can be observed from Fig. 2 that the symbols in blue area are mostly cross and square symbols of different wind comfort criteria, which indicates that pedestrian level wind environment in Hong Kong is very favourable for sitting long and sitting short. Besides, compared to the typical wind climate used in the study of Ratcliff and Peterka (1990), the pedestrian level wind environment in Hong Kong is a weak wind condition. It is obvious that the existing wind comfort criteria are limited in the application to the low wind environment of congested urban areas, like Hong Kong. In addition to this, the wind comfort criterion of Lawson (1978) is clearly more sensitive to the weak wind conditions in Hong Kong than other existing wind criteria because of the lower threshold wind velocity values.

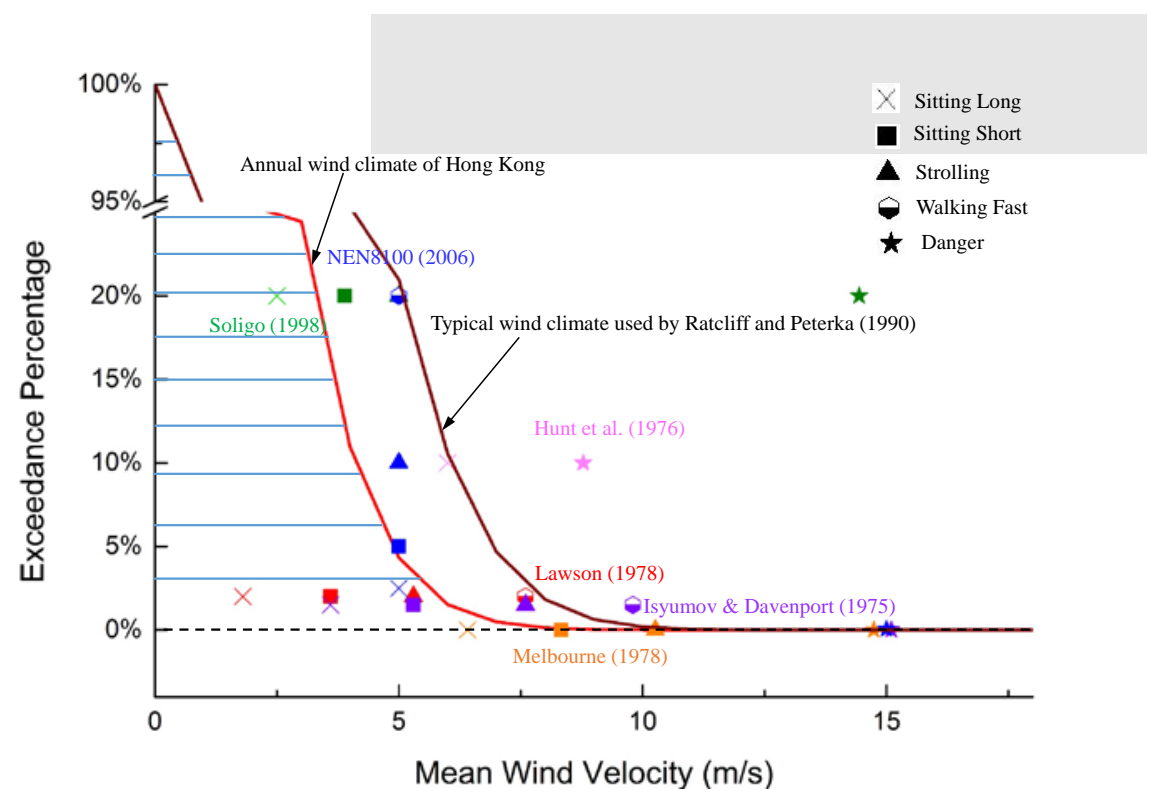

Fig. 2 Comparison of the wind comfort criteria: individual symbols represent the threshold values for different activities.

\section{Methodology}

\subsection{Threshold wind velocity parameters}

The mean wind velocity is used as the threshold wind velocity parameter instead of gust wind velocity or effective wind velocity, since it can readily combine with the meteorological data. The pedestrian level wind environment is often investigated at a scaled model in the wind tunnel test or the 
CFD numerical simulation. The mean wind velocity ratio $(M V R)$ is adopted here, which is defined as a function between the pedestrian wind velocity and the reference wind velocity. For the incident wind direction $i$, the scaled model investigated in the wind tunnel test or CFD numerical simulation and the in situ condition, the $M V R$ can be written as the flowing equations:

$$
\begin{gathered}
M V R_{i, S M}=U_{p i, S M} / U_{r i, S M} \\
M V R_{i, I S}=U_{p i, I S} / U_{r i, I S}
\end{gathered}
$$

where, $U_{p i}$, denotes the mean wind velocity at the pedestrian level, while $U_{r i}$ is the reference mean wind velocity of the approaching flow. The subscript "SM" stands for the scaled model investigated in wind tunnel test or CFD simulation and “IS" means the in situ wind environment. In a quality wind tunnel test or CFD simulation, the flowing equation is established [41]:

$$
M V R_{i, S M}=M V R_{i, I S}
$$

From the above equations, it can be concluded that the $M V R$ obtained from the scaled model can be employed as the evaluation parameter in the wind comfort assessment directly instead of converting it to the in situ condition. In addition to the threshold wind velocity parameter, the reference height for Hong Kong should be chosen carefully. In many practice of the wind comfort assessment, the reference height was determined by the height of meteorological station which maybe $10 \mathrm{~m}$ in situ condition [31, $34,48]$ or $60 \mathrm{~m}[29,41]$. Owing to the fact that as one of the densely-built mega-cities in the wold, the height of the Hong Kong's canopy layer at the metropolitan areas is more than 60m [49]. Besides, Hong Kong has more than 1,200 skyscrapers taller than 100 m [50]. Therefore, the reference height for Hong Kong is set to 200m in this study, which can be considered high enough to be not inferenced by urban blocks.

The investigation of different wind directions for the designated location are considered as a common practice in wind engineering [13, 17, 22, 42, 44, 51-56]. Instead of investigating the wind comfort in each wind directions, the overall mean wind velocity ratio $(O M V R)$ is employed here, which is determined by integrating the measured directional values of $M V R$ with their respective directional 
occurrence probabilities. The $O M V R$ is employed here due to the fact that the probability of occurrence for each approaching wind direction is likely different due to complex urban and topographical environment. The $O M V R$ is defined as the following equations:

$$
O M V R=\sum_{i=1}^{n} F_{i} \times M V R_{i, S M}
$$

where, $F_{i}$ is the probability of the approaching wind coming from $i$ direction. It can be obtained from site specific wind data or meteorological station. $F_{i}$ is computed from the hourly wind data of King's Park Meteorological Station of the Hong Kong Observatory (HKO) from 1993 to 2015 in this study, see Fig.3. $n$ denotes the number of wind directions that has been considered.

In order to represent the actual wind environment of the designated place, 16 wind directions are adopted here which corresponds with the Kubota et al. [17] , Bu et al. [42] and the requirement of AVA assessment scheme [9]. The OMVR used in this study is:

$$
O M V R=\sum_{i=1}^{16} F_{i} \times M V R_{i, S M}
$$

\subsection{Exceedance probability}

The statistical data of the wind velocity $U_{r i}$ for the 16 wind directions are believed to follow the two-parameter Weibull distribution $[33,36,42]$. The Weibull probability density function $p\left(U_{r i}\right)$ for each wind direction is defined as follows:

$$
p\left(U_{r i}\right)=F_{i}\left\{\frac{k_{i}}{c_{i}}\left(\frac{U_{r i}}{c_{i}}\right)^{k_{i}-1} \exp \left[-\left(\frac{U_{r i}}{c_{i}}\right)^{k_{i}}\right]\right\}
$$

where, $k_{i}$ is shape parameter and $c_{i}$ is the scale parameter. These two parameters are correlated to the mean wind velocity and the standard deviation in the following way:

$$
\begin{aligned}
& \overline{U_{r i}}=c_{i} \Gamma\left(1+\frac{1}{k_{i}}\right) \\
& \sigma_{i}^{2}=c_{i}^{2}\left[\Gamma\left(1+\frac{2}{k_{i}}\right)-\Gamma^{2}\left(1+\frac{1}{k_{i}}\right)\right]
\end{aligned}
$$

where, $\overline{U_{r i}}$ denotes for the mean wind velocity and ${\sigma_{i}}^{2}$ is the corresponding standard deviation. $\Gamma$ is the gamma function. 
The Weibull cumulative distribution is given by:

$$
P\left(U<U_{r i}\right)=F_{i}\left\{1-\exp \left[-\left(\frac{U_{r i}}{c_{i}}\right)^{k_{i}}\right]\right\}
$$

It is evident that the relationship between the wind velocity at pedestrian level and the wind velocity at reference height is linear. Based on the similarity theory, it can be deemed that the value of $M V R$ for each azimuth is a constant in most cases. Besides, the shape parameter $\left(k_{i}\right)$ of the Weibull distribution is considered to be the same for the site and meteorological station [57]. Therefore, the overall probability of exceeding certain scalar velocity $U_{r i}$ for 16 wind directions can be expressed by the following equations:

$$
P_{e x c}\left(U>U_{r i}\right)=\sum_{i=i}^{16} F_{i}\left\{\exp \left[-\left(\frac{U_{r i}}{c_{i}}\right)^{k_{i}}\right]\right\}
$$

By combining with Equation (5), the overall probability of exceeding certain scalar velocity $U_{p}$ at pedestrian level can be written as:

$$
P_{\text {exc }}\left(U>U_{p}\right)=\sum_{i=i}^{16} F_{i}\left\{\exp \left[-\left(\frac{U_{p}}{M V R_{i} \times c_{i}}\right)^{k_{i}}\right]\right\}
$$

\subsection{Wind climate of Hong Kong}

The wind climate of Hong Kong are obtained from calibrating the hourly wind data of the King's Park Meteorological Station of the HKO from 1993 to 2015. The location of the station and metadata of the site are documented in relevant publications $[58,59]$. Noted that the King's Park Meteorological Station is located near the HKPolyU campus and the wind observation data is more representative than other Meteorological Stations that are far from urban cities. The wind roses of four seasons for Hong Kong are presented in Fig.3, which are obtained from calibrating the hourly wind data of the King's Park Meteorological Station of the HKO from 1993 to 2015. It can be observed from Fig.3 that the prevailing wind for spring, autumn and winter seasons is from eastward and the prevailing wind for 
summer season is from westward. Thus, the wind environment of Hong Kong is similar in spring, autumn and winter seasons while quite different in summer season.

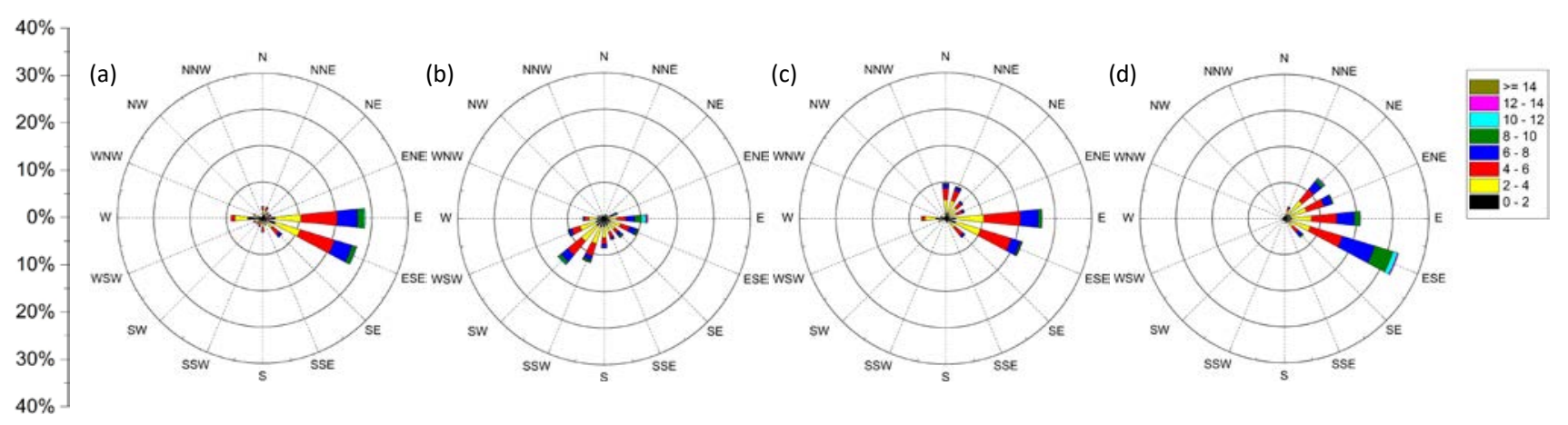

Fig.3 The wind rose with frequency distribution of hourly mean wind velocity for Hong Kong: (a) Spring (Mar.-May); (b) Summer (Jun.-Aug.); (c) Autumn (Sep.-Nov.); (d) Winter (Dec.-Feb.).

\subsection{Proposed wind comfort criteria for Hong Kong}

It should be noted that the proposed wind comfort criteria is based on the mechanical effect of wind upon people instead of focusing on the wind perception. The wind comfort criteria is classified into four groups for the summer (Jun-Aug): i) unfavourable wind environment for pedestrian activities caused by weak wind condition; ii) acceptable wind environment for pedestrian activities, including sitting long, sitting short and strolling; iii) tolerable wind environment for walking fast; iv) intolerable wind environment for any activity forms; v) dangerous to stay outdoors. As for the wind comfort criteria for winter (Dec-Feb), the categorizations are almost the same except the unacceptable condition for weak wind condition. The detailed description of this wind comfort criteria is presented in Table 7. The choices and reasons made for the wind comfort criteria are outlined below:

Choices made:

- The proposed wind comfort criteria are based on the assumption that the pedestrians are properly dressed and stayed under shaded conditions. The descriptions of pedestrian activities are referred to the reference [29].

- The threshold wind velocity parameter is designed to be convenient for the scaled model. $U_{r}$ denotes the wind velocity at the reference height (200m in prototype) for the assessment area. 
The threshold wind velocity values are not constants and need to be carefully calculated according to the local wind climate before the assessment procedure.

- The low wind threshold value of $1.5 \mathrm{~m} / \mathrm{s}$ and the exceedance probability of $50 \%$ is chosen for the unfavourable category in summer criteria. The parameters in Lawson (1978) criterion is chosen for acceptable, tolerable and intolerable category in the proposed criteria. The definitions of wind danger category in NEN 8100 criterion is chosen for danger category in the proposed criteria.

Reasons for the choices:

- The wind comfort criteria are proposed in seasonal (wind comfort criteria for summer and winter, respectively) for the following considerations: (i) the subtropical climate of Hong Kong makes the summer long and unbearable while the winter mild and temperate. The urban heat island (UHI) effect and the weak wind condition exacerbate the uncomfortable outdoor thermal environment in the summer, which means that wind is very much desired in the hot and humid summer [23]. According to the climate normal of Hong Kong, the average temperature in winter (Dec-Feb) is about $17{ }^{\circ} \mathrm{C}$ [60] and the pedestrians can achieve neutral comfort by wearing proper clothes in winter. (ii) Summer and winter seasons are the representative seasons of Hong Kong climate. There are almost only summer and winter seasons in Hong Kong and spring and autumn seasons are short enough to be negligible. Thus, these two seasons have received more attentions for achieving acceptable wind environment than the other two seasons [5, 22, 23]. (iii) As concluded in Section 3.3, the wind environment of Hong Kong is similar in spring, autumn and winter seasons while quite different in summer season.

- A low wind threshold value of $1.5 \mathrm{~m} / \mathrm{s}$ and the exceedance probability of $50 \%$ are adopted in the wind comfort criteria for summer. It is in accordance to the human minimum noticeable wind velocity [48] and corresponds to the requirement of AVA scheme [9]. Besides, these 
values satisfies the requirement of achieving neutral thermal sensation under a shaded condition in summer [23]. Therefore, a low wind threshold must be assured for the summer criteria.

- The parameters in Lawson (1978) criterion is chosen for acceptable, tolerable and intolerable category in the proposed criteria for the following considerations: (i) the comparison between the widely-used wind comfort criteria presented in Fig.2 illustrates that Lawson (1978) criterion is clearly more sensitive to the low wind environment in Hong Kong than others because of the lower threshold wind velocity values. (ii) The upper bound for strolling in Lawson (1978) criterion is 4Bft (about 5.3m/s), which represents the onset of discomfort according to Penwarden (1973) and Lawson (1978) [36, 61].

- The parameters of wind danger category in NEN 8100 criterion is chosen for danger category for the following considerations: (i) it has comprehensive definition of wind danger compared to other wind comfort criteria. (ii) It is dangerous for pedestrian to stay outdoors when the wind velocity is above $15 \mathrm{~m} / \mathrm{s}$. Therefore, the exceedance probability of $0.05 \%$ is adopted in the proposed criteria rather than $0.3 \%$.

Table 7. Proposed wind comfort criteria for Hong Kong

\begin{tabular}{|c|c|c|c|c|}
\hline \multicolumn{5}{|c|}{ Wind comfort criteria for summer (Jun-Aug) } \\
\hline Category & Threshold velocity & Exceedance probability & Activity description & Remark [48] \\
\hline Unfavourable & $O M V R<\frac{1.5}{U_{r}}$ & $50 \%$ & N/A & $\begin{array}{l}\text { No noticeable } \\
\text { wind }\end{array}$ \\
\hline \multirow{3}{*}{ Acceptable } & $O M V R<\frac{1.8}{U_{r}}$ & $2 \%$ & Sitting Long & Light breeze \\
\hline & $O M V R<\frac{3.6}{U_{r}}$ & $2 \%$ & Sitting Short & Gentle breeze \\
\hline & $O M V R<\frac{5.3}{U_{r}}$ & $2 \%$ & Strolling & $\begin{array}{l}\text { Moderate } \\
\text { breeze }\end{array}$ \\
\hline Tolerable & $O M V R<\frac{7.6}{U_{r}}$ & $2 \%$ & Walking Fast & Fresh breeze \\
\hline Intolerable & $O M V R>\frac{7.6}{U_{r}}$ & $2 \%$ & $\begin{array}{l}\text { Not suitable for } \\
\text { activities }\end{array}$ & Strong breeze \\
\hline Danger & $O M V R>\frac{15}{U_{r}}$ & $0.05 \%$ & Dangerous & Gale \\
\hline \multicolumn{5}{|c|}{ Wind comfort criteria for winter (Dec-Feb) } \\
\hline Category & Threshold velocity & Exceedance probability & Activity description & Remark [48] \\
\hline
\end{tabular}




\begin{tabular}{lllll}
\hline Acceptable & $O M V R<\frac{1.8}{U_{r}}$ & $2 \%$ & Sitting Long & Light breeze \\
Tolerable & $O M V R<\frac{3.6}{U_{r}}$ & $2 \%$ & Sitting Short & Gentle breeze \\
Intolerable & $O M V R<\frac{5.3}{U_{r}}$ & $2 \%$ & Strolling & $\begin{array}{l}\text { Moderate } \\
\text { breeze }\end{array}$ \\
\hline Danger & $O M V R>\frac{7.6}{U_{r}}$ & $2 \%$ & Walking Fast & Fresh breeze \\
& $O M V R$ & $2 \%$ & $\begin{array}{l}\text { Not suitable for } \\
\text { activities }\end{array}$ & Strong breeze \\
\hline
\end{tabular}

\section{Application for the proposed criteria - Case study}

\subsection{Wind tunnel test}

The wind tunnel tests of the HKPolyU campus model are selected as the case study to demonstrate the proposed wind comfort criteria because of its location in midtown area of Hong Kong. The mean wind velocity measurements at pedestrian level were carried out in the low-speed section of CLP Power Wind/Wave Tunnel Facility (WWTF) at Hong Kong University of Science and Technology (HKUST). This wind tunnel is a closed circuit subsonic boundary layer wind tunnel which has two parallel test sections: a high-speed test section and a low-speed test section, for civil, structural and environmental engineering applications. The tests were performed under the turbulence wind flow which was generated by a series of roughness elements and spires placed in the upstream test section, see Fig.4 (a).

\subsubsection{Test design}

The HKPolyU campus model with its surroundings were scaled and fabricated at 1:200 ratio and the range of the model has a diameter of 10 kilometres in prototype. The model was replicated in great detail, any feature that greater than one meter in prototype was carefully reproduced. The test photo of the HKPolyU campus model is presented in Fig.4 (a). Besides, the similarity requirements were examined with great care during the tests. The geometric and boundary layer flow similarities can be 
easily achieved when the scaled model and boundary conditions are appropriately selected. The blockage ratio of the test is $4.5 \%$, which is less than $10 \%$ to minimize the influence of the constraining effects [62]. The Reynolds Number $(\mathrm{Re})$ in the test was over $7.1 \times 10^{4}$, which was sufficiently large enough to obtain Re independence according to the Australasian Wind Engineering Society (AWES) Quality Assurance Manual [63].

\subsubsection{Simulated atmospheric boundary layer}

Prior to the tests of the mean wind velocity at pedestrian level in the HKPolyU campus model, the incident vertical mean wind velocity profile and turbulence intensity profile of the atmospheric boundary layer were calibrated first. The wind tunnel tests were carried out in 16 wind directions at an interval of $22.5^{\circ}$ from $0^{\circ}$ (north) to $360^{\circ}$. The mean wind velocity profile followed the form of the power law:

$$
\frac{U(Z)}{U_{\text {ref }}}=\left(\frac{Z}{Z_{\text {Ref }}}\right)^{\alpha}
$$

where, $U_{\text {ref }}$ denotes the mean wind velocity at the reference height; $Z_{R e f}$ is the reference height which is $200 \mathrm{~m}$ in prototype (1m at model scale); $U(Z)$ is the mean wind velocity at the height of $Z$; $\alpha$ is the power law exponent. The turbulence intensity profile also varies with height in the form of power law relationship with the negative value of the power law exponent. In order to study the wind environment of the HKPolyU model, two wind profiles were obtained by grouping and fitting the wind profiles acquired from previous topographic study. Profile A for the incident wind direction $0^{\circ}, 45^{\circ}, 90^{\circ}, 112.5^{\circ}$, $135^{\circ}, 180^{\circ}, 202.5^{\circ}, 225^{\circ}, 292.5^{\circ}$, and Profile $\mathrm{B}$ for the remaining incident wind direction. The reference mean wind velocity $\left(U_{r e f}\right)$ were approximately $8 \mathrm{~m} / \mathrm{s}$ for all the tests. The measured values and the targeted values of the two wind profile are presented in Fig.4 (b). The errors shown in Fig.4 (b) were within $5 \%$, suggesting the reliability of the tests. 
(a)

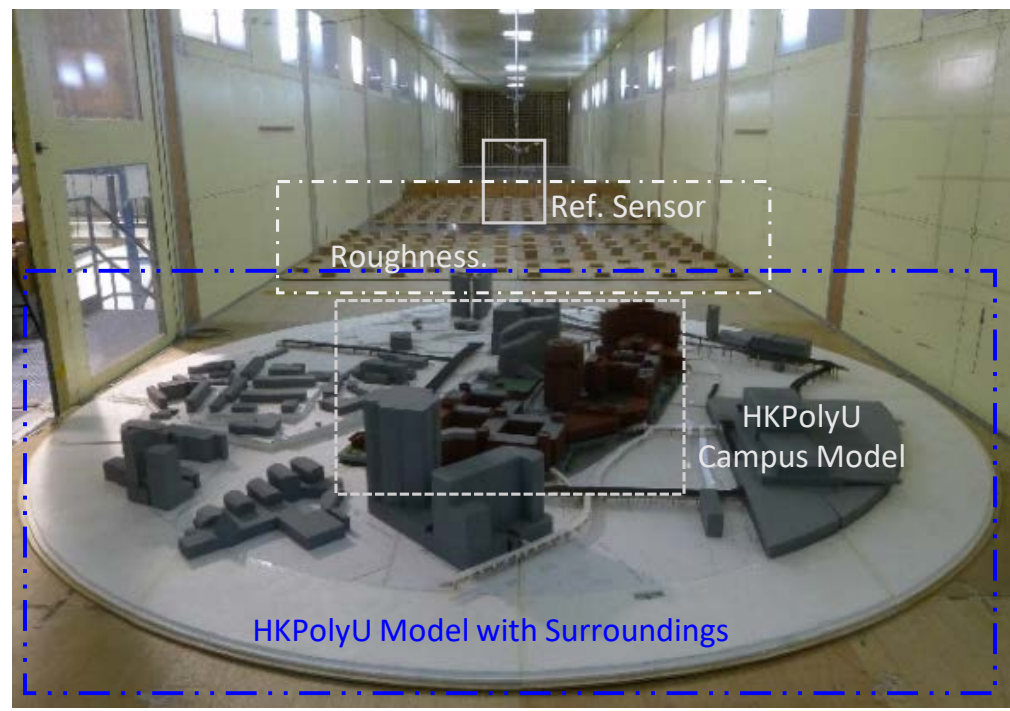

(b)

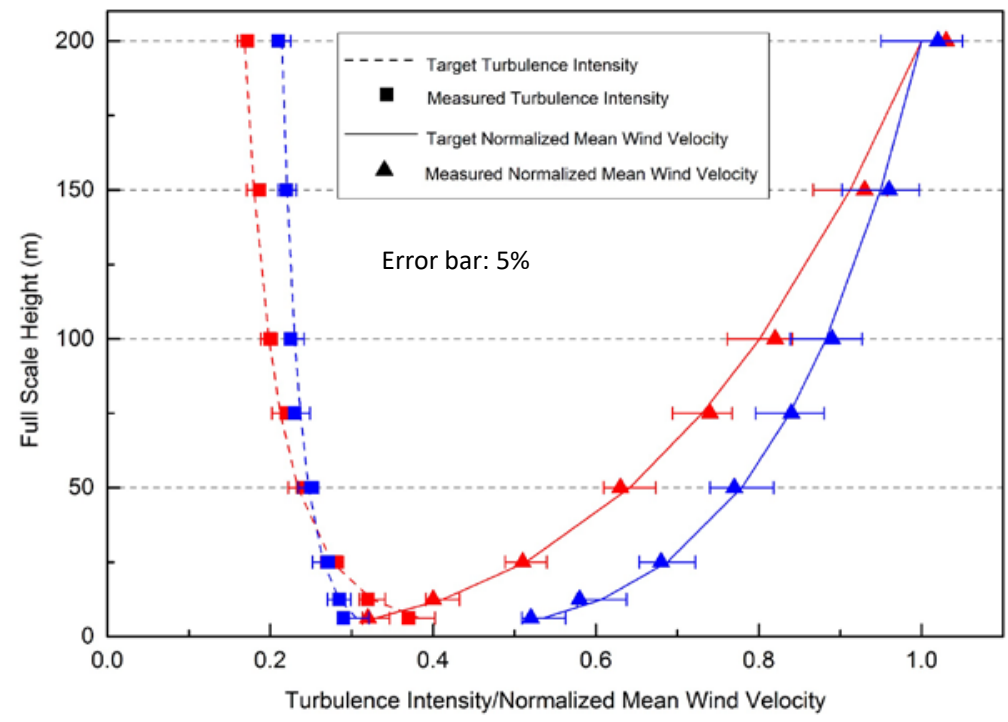

Fig.4 (a) Wind tunnel test photo of the HKPolyU campus model: approaching wind direction $0^{\circ}$ (wind from north); (b) Approaching wind profiles of the wind tunnel test: red for Profile A, blue for Profile B.

70 Kanomax velocity sensors were used in this study at pedestrian level for measurements $(0.01 \mathrm{~m}$ above the ground in the model scale). Prior to the pedestrian level wind velocity measurements, all the Kanomax velocity sensors used during the test were firstly calibrated against a Cobra Probe sensor. It should be mentioned that Cobra Probe sensor is believed to be accurate enough to be used as the calibration sensor. The calibration photo and results are presented in Fig. 5. The results show that the 
maximum discrepancies between the Kanomax velocity sensors and the reference sensors are almost within $5 \%$, which suggests the reliability of the measurements.

(a)

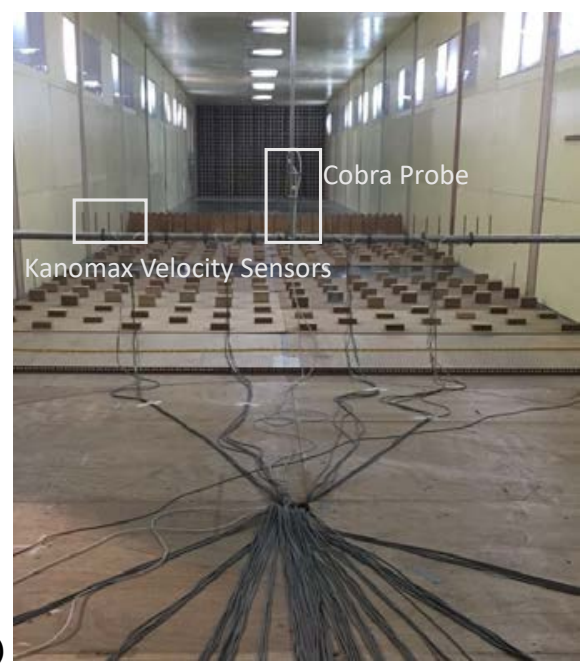

(b)

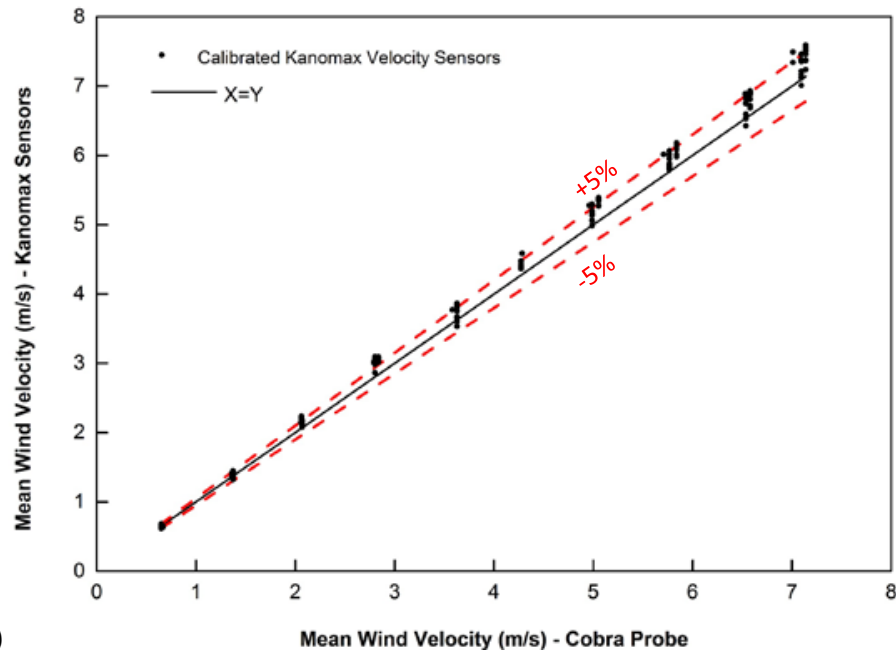

Fig. 5 Calibration of Kanomax velocity sensors: (a) Calibration photo; (b) Calibration results between Kanomax velocity sensors and the reference sensor.

During the tests, one Kanomax velocity sensor and one cobra probe were used as the reference velocity sensors ( $1 \mathrm{~m}$ above the ground in the model scale). The distributions of the Kanomax velocity sensors are indicated in blue points in Fig. 6. In addition, it can be found that there are some measurement points underneath the building block. This is due to the fact that these points are located in the lift-up areas, in which the building blocks are "lifted off” the ground by modern pillar structures, as can be seen from the left photo in Fig.6. Furthermore, the photos of other locations at the campus, like lawn and square are also indicated in Fig.6. 


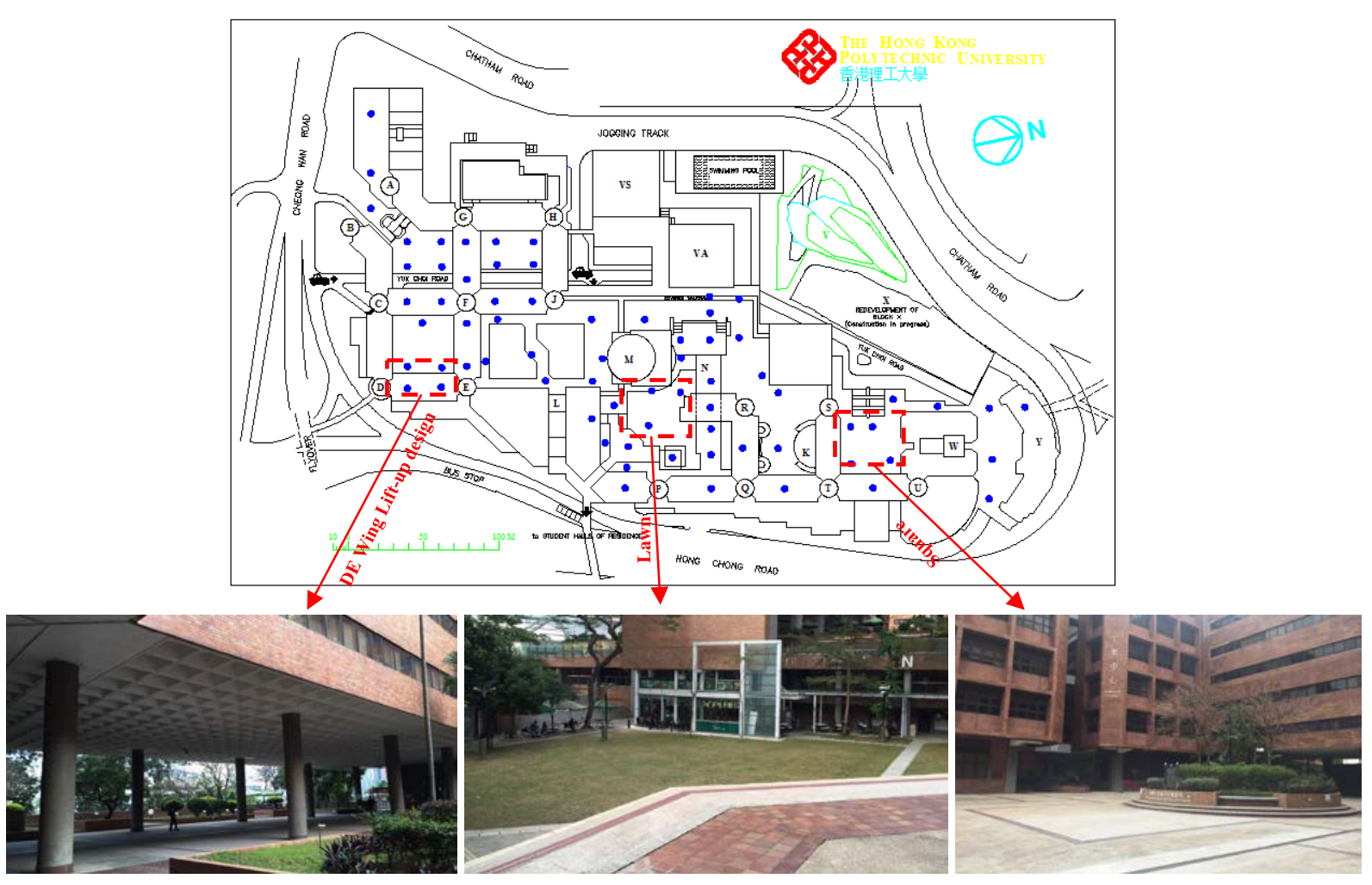

Fig. 6 Sensor locations and photos of the HKPolyU campus model.

4.2 Wind comfort assessment results

4.2.1 Wind tunnel test results

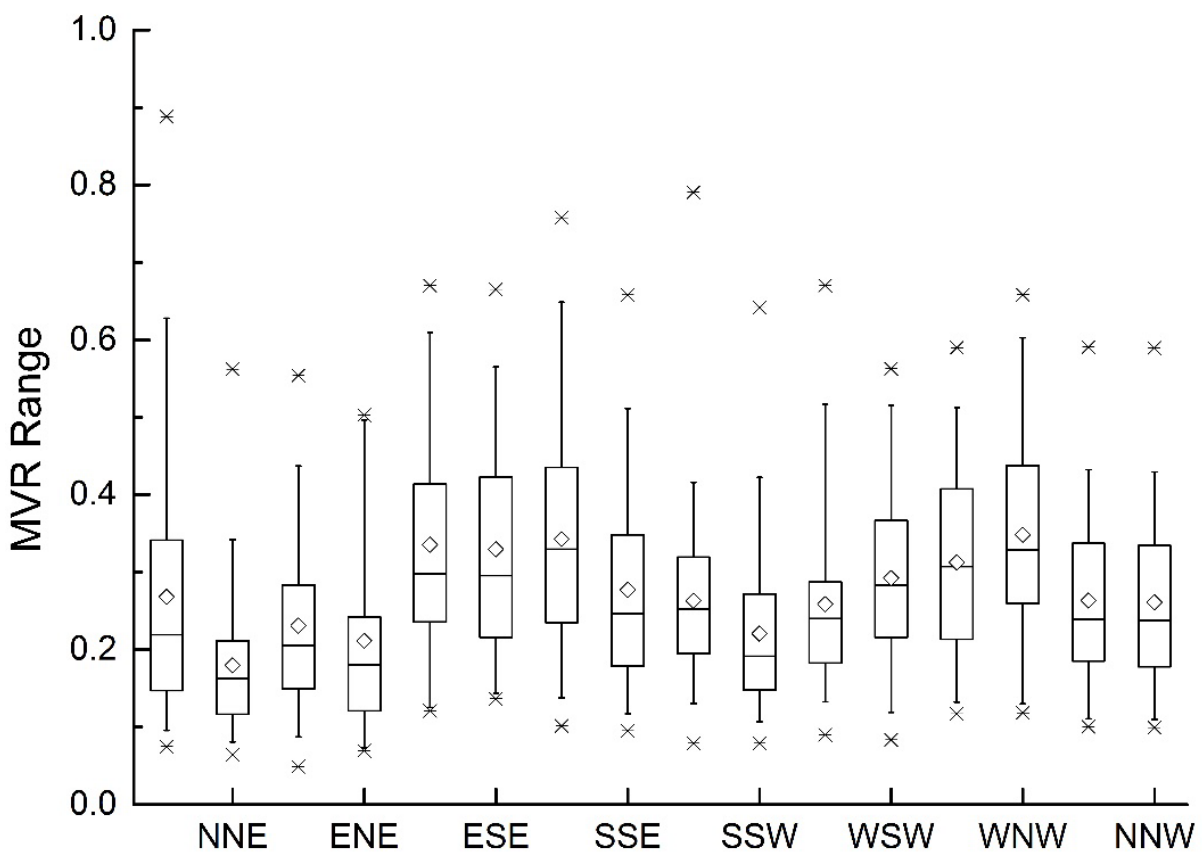

Fig. 7 Box plots of $M V R$ results in wind tunnel tests for 16 incident wind directions: the box edges represent the 25th and 75th percentiles, the whiskers for the 5th and 95th percentiles, the lines in the boxes for median values, and the symbols $(\diamond)$ for mean values. 
The results of the $M V R$ are presented in box plots in Fig. 7. It can be observed that most values of the $M V R$ are within the range from 0.1 to 0.4 . Given the fact that the annual average mean wind velocity of the HKPolyU campus at $200 \mathrm{~m}$ above the ground is $5 \mathrm{~m} / \mathrm{s}$ obtained from the hourly wind data of the King's Park Meteorological Station from 1993 to 2015, most of the mean wind velocity at pedestrian level measured during the tests are within the range from $0.5 \mathrm{~m} / \mathrm{s}$ to $2 \mathrm{~m} / \mathrm{s}$. Therefore, the pedestrian level wind environment in the HKPolyU campus can be deemed as low wind condition. Besides, it can be found from Fig. 6 that different incident wind direction results in different $M V R$ values due to the different blockage effect of the surrounding buildings. The values of $M V R$ are higher when the approaching wind comes from SE and WNW while the values of $M V R$ are lower when the approaching wind comes from NNE, ENE and SSW.

\subsubsection{Assessment results for summer (Jun-Aug)}

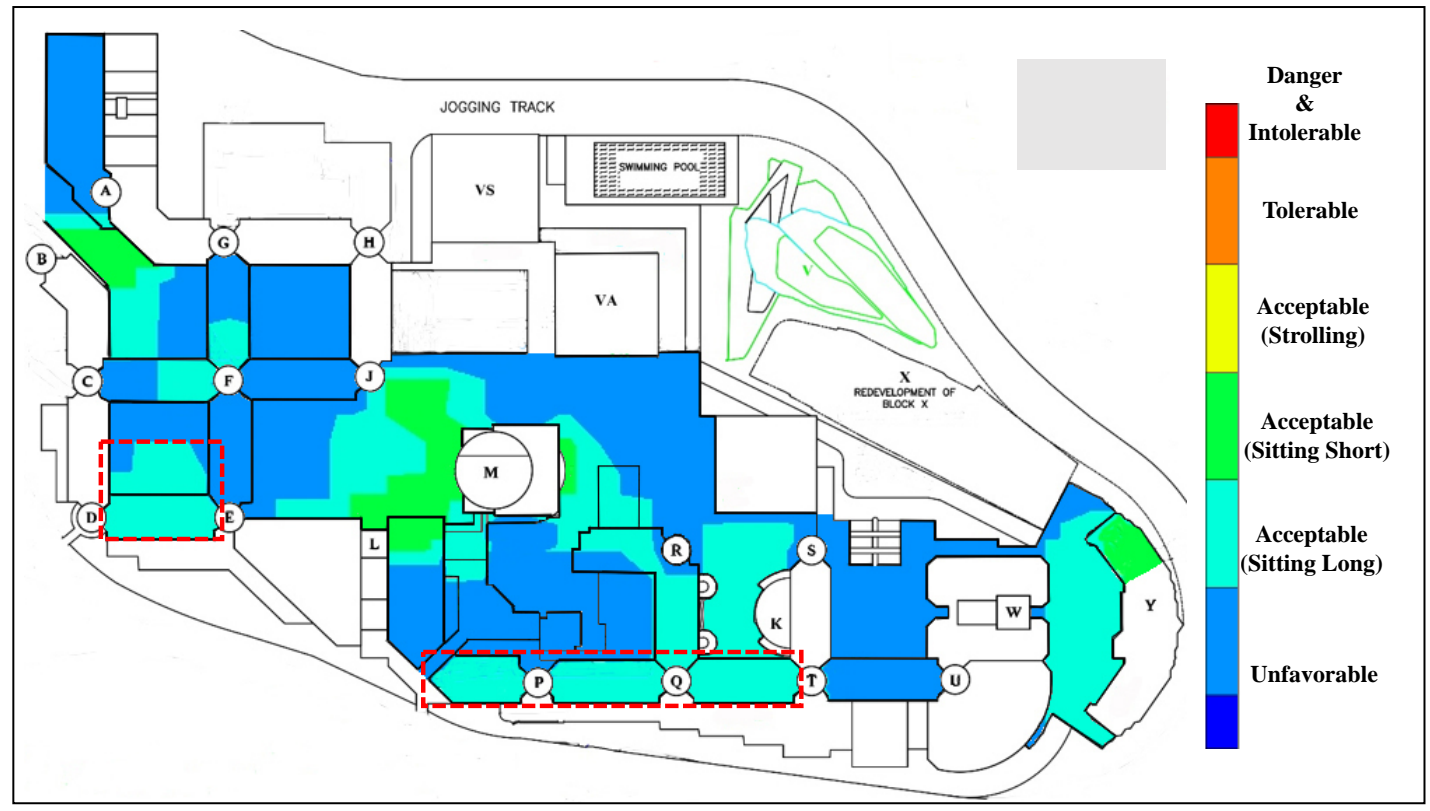

Fig. 8 Assessment results of the pedestrian level wind comfort for summer

Fig. 8 presents the results of the pedestrian level wind comfort assessment for the HKPolyU campus model in the summer by the proposed criteria. It can be observed that the wind comfort have three 
levels at the campus: unfavourable, acceptable (sitting long) and acceptable (sitting short). There are considerable places at the campus that have weak wind environment and it is unfavourable for any pedestrian activities in the hot and humid summer. However, the wind environment of the lift-up areas underneath the PQ, QR, QT, and DE wings (areas in the red-dashed boxes) are comfortable for sitting long, which also suggests suitable places for holding some outdoor activities in the summer as explained in our previous study [5]. Apart from these lift-up areas, places on podium floor at the campus (areas in light-blue colour) are comfortable for sitting long. Furthermore, the middle part of the campus around $\mathrm{M}$ building, the lift-up area underneath the Y building and the area between $\mathrm{A}$ and B building (areas in green colour) have relatively higher wind velocity than the other places at the campus. Thus, only sitting for short time is preferred in these areas. Although no official questionnaire survey has been carried out for studying wind comfort at the HKPolyU campus specifically, the above assessment results correspond with the experience and observations of the staffs and students of the HKPolyU and they are also consistent with our previous research [5].

\subsubsection{Assessment results for winter (Dec-Feb)}

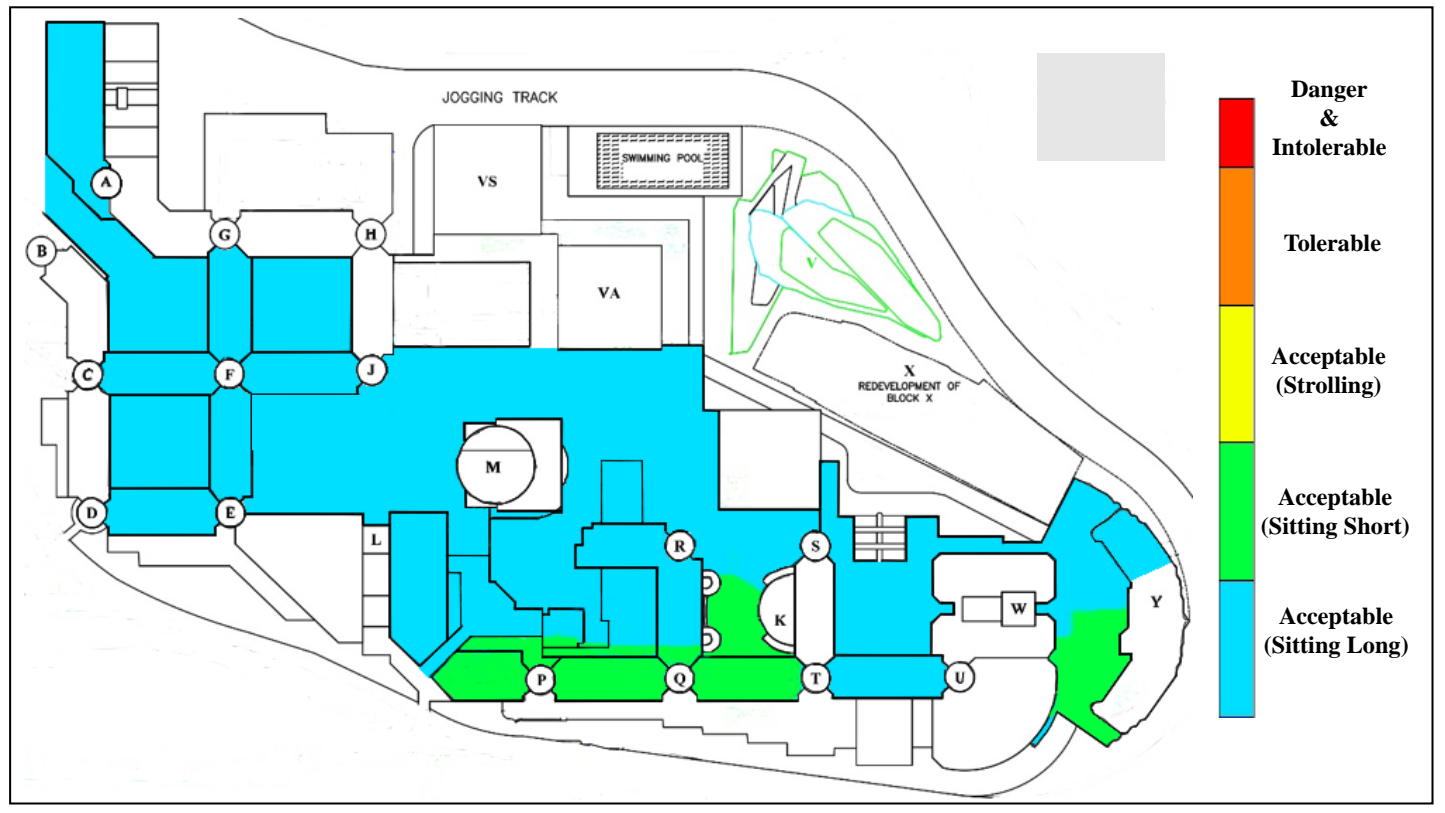

Fig. 9 Assessment results of the pedestrian level wind comfort for winter 
The results of the pedestrian level wind comfort assessment for the HKPolyU campus in winter is shown in Fig. 9. It can be found that the wind environment of the majority of places at campus are comfortable for sitting long. The lift-up areas underneath the P core, PQ wing, QT wing and the podium areas around $\mathrm{Y}$ building (areas in green colour) have relatively higher wind velocity environment than the other places. Therefore, the above higher wind velocity areas are only comfortable for sitting short. This can be partly accounted for the fact that the prevailing wind of the HKPolyU campus in the winter comes from ESE, as can be seen in Fig.6 (b). In addition, it should be mentioned that there is no strong wind area at the campus that cause wind nuisance for the pedestrian in winter.

\subsubsection{Wind comfort assessment results by NEN 8100 [41]}

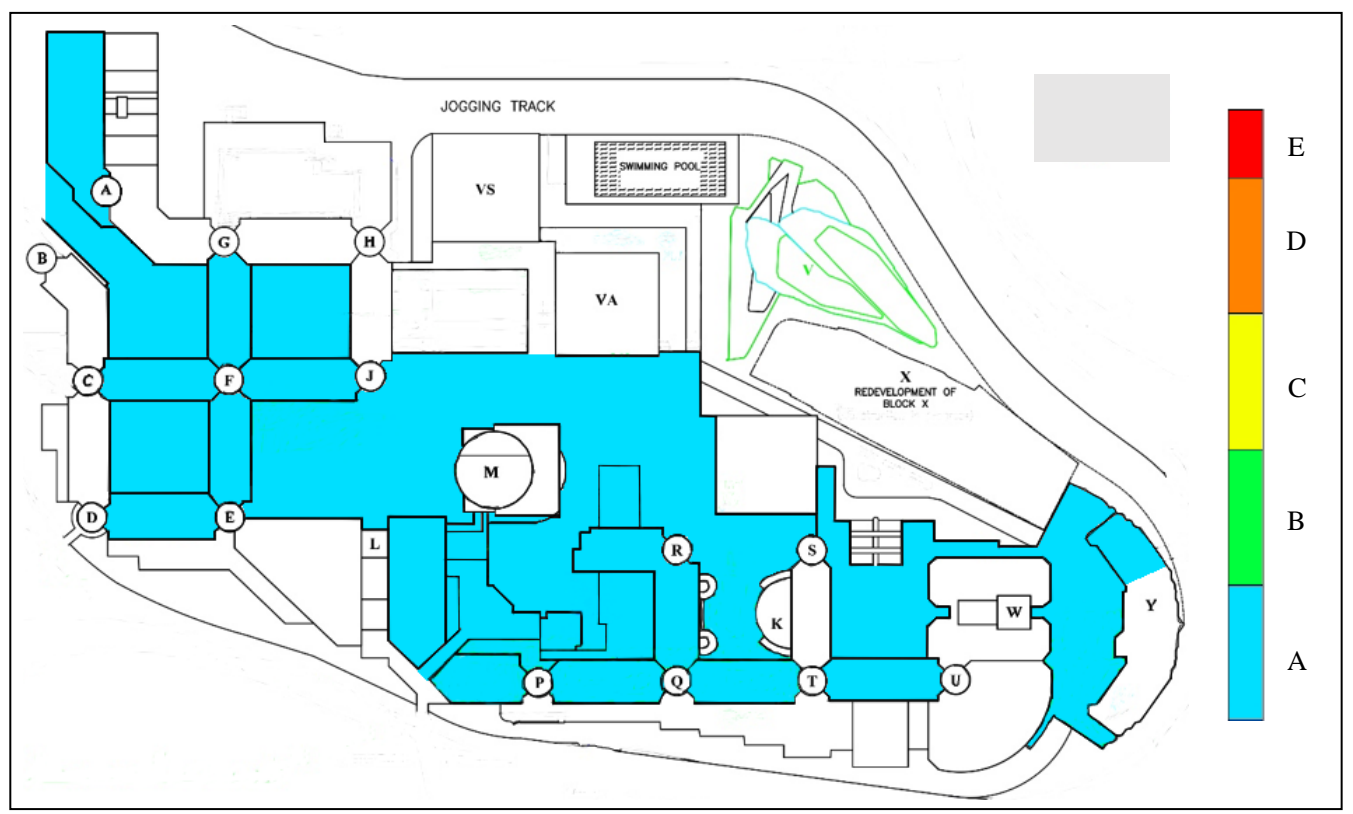

Fig. 10 Assessment results of the pedestrian level wind comfort by NEN8100

The wind comfort of the HKPolyU campus assessed by the NEN 8100 (2006) is presented here in order to make a comparison with the proposed criteria. The NEN 8100 (2006) wind comfort criterion is based on an extensive work of the researchers, including Verkaik [64, 65] and Willemsen and Wisse [41]. Besides, it has been broadly adopted to evaluate the pedestrian level wind comfort in many researches [14, 27, 41, 53, 56]. The assessment results of the HKPolyU campus model by the wind 
comfort criterion NEN 8100 is shown in Fig. 10. It should be mentioned that the assessment procedure of NEN 8100 criterion does not differentiate summer and winter. Thus, the wind data obtained from the HKO is re-processed to fit the Equation (14). It is clear that the level of wind comfort for the whole campus is classified as grade A, which means that the wind environment is very good for pedestrian activities, including traversing, strolling and sitting. However, this assessment result is inadequate for representing the unfavourable weak wind conditions in summer and the low wind environment in Hong Kong, which also corresponds with the findings from Fig.2.

\section{Conclusions}

This paper sets out to investigate suitable wind comfort criterion for the high-rise subtropical cities, like Hong Kong. Owing to the climatic conditions and the congested wind flow, the wind comfort criteria adopted by overseas are not suitable for assessing this low wind condition. The wind comfort criteria proposed in this paper adopts $O M V R$ as the threshold wind velocity parameter, which considers the occurrence frequency of the approaching wind direction. Besides, the direct use of $O M V R$ in the proposed criteria instead of converting it to the actual wind velocity provides a convenient and effective method for the scaled model cases. It should be mentioned that the threshold values of the proposed criteria should be carefully defined before the assessment. Furthermore, the exceedance probability of the proposed criteria follows the two-parameter Weibull distribution. In addition, the proposed wind comfort criteria distinguished from the other wind comfort criteria in the following two aspects: one is that the wind comfort criteria are based on seasons (summer and winter, respectively) and the other one is that when the wind velocity lower than $1.5 \mathrm{~m} / \mathrm{s}$ for over $50 \%$ of the time is conceived as unfavourable for pedestrian activities in the hot and humid summer. The parameters of threshold wind velocity and exceedance probability are carefully chosen from existing wind comfort criteria, which provide scientific foundation for the proposed wind comfort criteria. Besides, these parameters are adapted to suitably assessing weak wind condition. Meanwhile, the proposed wind 
comfort criteria also indicate that the application of the wind comfort criteria to a designated area should take the local wind climate into consideration.

The wind environment of the HKPolyU campus model is selected as a case study and the wind tunnel tests were conducted to measure the values of $O M V R$ at the pedestrian level. The measured values of $O M V R$ are then employed to assess the wind comfort at the HKPolyU campus by the proposed wind comfort criteria and also by the NEN8100 criterion for comparison. The results demonstrate that the proposed wind comfort criteria can assess the weak wind environment more suitably than NEN 8100 criterion. It should be mentioned that this paper mainly focused on presenting the proposed wind comfort criteria, the respondent survey and the implication of the criteria will be included in the future works.

The proposed criteria corresponds to the government policies of enhancing ventilation in the city and it can help the urban planners and policy-makers better understanding the pedestrian level wind comfort in the city. The findings of this study may also be useful in providing scientific basis and reference for future enhancement of the AVA scheme and other building community guidelines in Hong Kong as appropriate, as well as for the development of impact-based forecasts [66]. Even though the proposed criteria are meant for the densely-built subtropical urban cities, like Hong Kong, the methodology that has been used in this paper can be applied to other places around the world. However, the parameters of the criteria should be chosen according to the local environment carefully.

\section{Acknowledgement}

The work described in this paper was fully supported by a grant from the Research Grants Council of the Hong Kong Special Administrative Region, China (Project No. C5002-14G). The authors would also like to thank the Hong Kong Observatory for providing the wind data of King's Park Meteorological Station for this study.

\section{References}

[1] Makaremi N., Salleh E., Jaafar M. Z., GhaffarianHoseini, A. (2012). Thermal comfort conditions of shaded outdoor spaces in hot and humid climate of Malaysia. Build. Environ., 48, 7-14. 
[2] Villadiego K., Velay-Dabat M. A. (2014). Outdoor thermal comfort in a hot and humid climate of Colombia: a field study in Barranquilla. Build. Environ., 75, 142-152.

[3] Wong N. H., Feriadi H., Lim P. Y., Tham K. W., Sekhar C., Cheong K. W. (2002). Thermal comfort evaluation of naturally ventilated public housing in Singapore. Build. Environ., 37(12), 1267-1277.

[4] Hwang R. L., Lin, T. P. (2007). Thermal comfort requirements for occupants of semi-outdoor and outdoor environments in hot-humid regions. Archit. Sci. Rev., 50(4), 357-364.

[5] Niu J., Liu J., Lee T. C., Lin Z. J., Mak C. M., Tse K. T., Tang B. C, Kwok K. C. (2015). A new method to assess spatial variations of outdoor thermal comfort: onsite monitoring results and implications for precinct planning. Build. Environ., 91, 263-270.

[6] Stathopoulos, T. (2006). Pedestrian level winds and outdoor human comfort. J. Wind Eng. Ind. Aerod., 94(11), 769-780.

[7] Ai Z. T., Mak C. M. (2015). From street canyon microclimate to indoor environmental quality in naturally ventilated urban buildings: issues and possibilities for improvement. Build. Environ., 94, 489-503.

[8] Hang J., Li Y.G. (2010). Ventilation strategy and air change rates in idealized high-rise compact urban areas. Build. Environ., 45(12), 2754-2767.

[9] Ng E. (2009). Policies and technical guidelines for urban planning of high-density cities-air ventilation assessment (AVA) of Hong Kong. Build. Environ., 44(7), 1478-1488.

[10] Ai Z. T., Mak C. M. (2017). CFD simulation of flow in a long street canyon under a perpendicular wind direction: Evaluation of three computational settings. Build. Environ., 114, 293-306.

[11] Cui D. J., Mak C. M., Kwok K. C. S., Ai Z. T. (2016). CFD simulation of the effect of an upstream building on the inter-unit dispersion in a multi-story building in two wind directions. J. Wind Eng. Ind. Aerod., 150, 3141.

[12] Wu, Y., Niu. J.L. (2017). Numerical study of inter-building dispersion in residential environments: Prediction methods evaluation and infectious risk assessment. Build. Environ., 115, 199-214.

[13] Mu D., Gao N.P., Zhu T. (2016). Wind tunnel tests of inter-flat pollutant transmission characteristics in a rectangular multi-storey residential building, part A: Effect of wind direction. Build. Environ., 108, 159-170.

[14] Blocken B., Stathopoulos T., Van Beeck, J. P. A. J. (2016). Pedestrian-level wind conditions around buildings: Review of wind-tunnel and CFD techniques and their accuracy for wind comfort assessment. Build. Environ., 100, 50-81.

[15] Bottema M. (2000). A method for optimisation of wind discomfort criteria. Build. Environ., 35(1), 1-18.

[16] Iqbal Q. M. Z., Chan A. L. S. (2016). Pedestrian level wind environment assessment around group of highrise cross-shaped buildings: Effect of building shape, separation and orientation. Build. Environ., 101, 45-63.

[17] Kubota T., Miura M., Tominaga Y., Mochida A. (2008). Wind tunnel tests on the relationship between building density and pedestrian-level wind velocity: Development of guidelines for realizing acceptable wind environment in residential neighborhoods. Build. Environ., 43(10), 1699-1708.

[18] Mochida A., Lun I. Y. (2008). Prediction of wind environment and thermal comfort at pedestrian level in urban area. J. Wind Eng. Ind. Aerod., 96(10), 1498-1527.

[19] Reiter, S. (2010). Assessing wind comfort in urban planning. Environment and Planning B: Planning and Design, 37(5), 857-873.

[20] Ricci A., Burlando M., Freda A., Repetto M. P. (2017). Wind tunnel measurements of the urban boundary layer development over a historical district in Italy. Build. Environ., 111, 192-206.

[21] Yuan C., Ng E. (2012). Building porosity for better urban ventilation in high-density cities-A computational parametric study. Build. Environ., 50, 176-189.

[22] Du Y.X, Mak, C. M., Liu, J.L., Xia, Q., Niu, J.L., Kwok K. C. S. (2017). Effects of lift-up design on pedestrian level wind comfort in different building configurations under three wind directions. Build. Environ., 117, 84-99.

[23] Ng E., Cheng V. (2012). Urban human thermal comfort in hot and humid Hong Kong. Energy Build., 55, 51-65.

[24] Hang J., Li Y., Sandberg M., Claesson L. (2010). Wind conditions and ventilation in high-rise long street models. Build. Environ., 45(6), 1353-1365.

[25] Chan H. S., M. H. Kok, T. C. Lee, Temperature trends in Hong Kong from a seasonal perspective. Clim. Res., 55, (2012) 53-63.

[26] Lee T.C., K.Y. Chan, and E.W.L. Ginn, Projections of extreme temperature events in Hong Kong in the 21st century. Acta Meteor. Sinica (English Edition), 25(1), (2011) 1-20. 
[27] Blocken B., Janssen W. D., van Hooff T. (2012). CFD simulation for pedestrian wind comfort and wind safety in urban areas: General decision framework and case study for the Eindhoven University campus. Environ. Modell. Softw., 30, 15-34.

[28] Tsang C. W., Kwok K. C., Hitchcock, P. A. (2012). Wind tunnel study of pedestrian level wind environment around tall buildings: Effects of building dimensions, separation and podium. Build. Environ., 49, 167-181.

[29] Janssen W. D., Blocken B., van Hooff T. (2013). Pedestrian wind comfort around buildings: Comparison of wind comfort criteria based on whole-flow field data for a complex case study. Build. Environ., 59, 547-562. [30] Koss H. H. (2006). On differences and similarities of applied wind comfort criteria. J. Wind Eng. Ind. Aerod., 94(11), 781-797.

[31] Melbourne W. H. (1978). Criteria for environmental wind conditions. J. Wind Eng. Ind. Aerod., 3(2-3), 241-249.

[32] Ratcliff M. A., Peterka J. A. (1990). Comparison of pedestrian wind acceptability criteria. J. Wind Eng. Ind. Aerod., 36, 791-800.

[33] Sanz-Andres A., Cuerva A. (2006). Pedestrian wind comfort: Feasibility study of criteria homogenisation. J. Wind Eng. Ind. Aerod., 94(11), 799-813.

[34] Isyumov N., Davenport A. G. (1975). The ground level wind environment in built-up areas. In Proc. 4th Int. Conf. on Wind Effects on Buildings and Structures, Heathrow (pp. 403-422).

[35] Gandemer J. (1975). Wind environment around buildings: aerodynamic concepts. In Proc., 4th Int. Conf. Wind Effects on Buildings and Structures, Heathrow (pp. 423-432).

[36] Lawson T. V. (1978). The widn content of the built environment. J. Wind Eng. Ind. Aerod., 3(2-3), 93-105. [37] Hunt J. C. R., Poulton E. C. Mumford, J. C. (1976). The effects of wind on people; new criteria based on wind tunnel experiments. Build. Environ., 11(1), 15-28.

[38] Murakami S., Iwasa Y., Morikawa Y. (1986). Study on acceptable criteria for assessing wind environment at ground level based on residents' diaries. J. Wind Eng. Ind. Aerod., 24(1), 1-18.

[39] Soligo M. J., Irwin P. A., Williams C. J. (1993, December). Pedestrian comfort including wind and thermal effects. In Third Asia-Pacific Symposium on Wind Engineering.

[40] Durgin F. H. (1997). Pedestrian level wind criteria using the equivalent average. J. Wind Eng. Ind. Aerod., 66(3), 215-226.

[41] Willemsen E., Wisse J. A. (2007). Design for wind comfort in The Netherlands: Procedures, criteria and open research issues. J. Wind Eng. Ind. Aerod., 95(9), 1541-1550.

[42] Bu Z., Kato S., Ishida Y., Huang H. (2009). New criteria for assessing local wind environment at pedestrian level based on exceedance probability analysis. Build. Environ., 44(7), 1501-1508.

[43] Ohba M., Kobayashi N., Murakami S. (1988). Study on the assessment of environmental wind conditions at ground level in a built-up area-based on long-term measurements using portable 3-cup anemometers. J. Wind Eng. Ind. Aerod., 28(1-3), 129-138.

[44] HKPD, Feasibility Study for Establishment of Air Ventilation Assessment System, Final Report, the Government of the Hong Kong Special Adminis- trative Region, Hong Kong Planning Department, 2005. http://www.pland.gov.hk/pland_en/p_study/comp_s/avas/papers\%26reports/final_report.pdf

[45] Ginn W.L., T.C. Lee, K.Y. Chan, Past and Future Changes in the Climate of Hong Kong, Acta Meteor. Sinica (English Edition), 24(2), (2010) 163-175.

[46] Soligo M. J., Irwin P. A., Williams C. J., Schuyler G. D. (1998). A comprehensive assessment of pedestrian comfort including thermal effects. Journal of Wind Engineering and Industrial Aerodynamics, 77, 753-766.

[47] HK SAR Government, Code of Practice on Wind Effects in Hong Kong 2004. <http://www.bd.gov.hk/ english/documents/code/windcode2004.pdf>, 2004 (accessed on January 2017).

[48] Lawson T. V., Penwarden A. D. (1975, September). The effects of wind on people in the vicinity of buildings. In Proceedings 4th international conference on wind effects on buildings and structures (pp. 605622).

[49] Ng E., Yuan C., Chen L., Ren C., Fung, J. C. (2011). Improving the wind environment in high-density cities by understanding urban morphology and surface roughness: a study in Hong Kong. Landsc. Urban Plan., 101(1), 59-74.

[50] Wikipedia, List of tallest buildings in Hong Kong. <https://en.wikipedia.org/wiki/List_of_tallest_ buildings_in_Hong_Kong>, 6 March 2017 (accessed on March 2017).

[51] Ai Z. T., Mak C. M. (2014). A study of interunit dispersion around multistory buildings with single-sided ventilation under different wind directions. Atmos. Environ., 88, 1-13. 
[52] Bady M., Kato S., Takahashi T., Huang H. (2011). Experimental investigations of the indoor natural ventilation for different building configurations and incidences. Build. Environ., 46(1), 65-74.

[53] Blocken B., Persoon J. (2009). Pedestrian wind comfort around a large football stadium in an urban environment: CFD simulation, validation and application of the new Dutch wind nuisance standard. J. Wind Eng. Ind. Aerod., 97(5), 255-270.

[54] Hang J., Luo Z.W., Sandberg M., Gong J. (2013). Natural ventilation assessment in typical open and semiopen urban environments under various wind directions. Build. Environ., 70, 318-333.

[55] Wang B., Etheridge D. W., Ohba M. (2011). Wind tunnel investigation of natural ventilation through multiple stacks. Part 1: Mean values. Build. Environ., 46(7), 1380-1392.

[56] Zheng C., Li Y., Wu Y. (2016). Pedestrian-level wind environment on outdoor platforms of a thousandmeter-scale megatall building: Sub-configuration experiment and wind comfort assessment. Build. Environ., 106, 313-326.

[57] Pietrzyk K., Hagentoft C. E. (2008). Probabilistic analysis of air infiltration in low-rise buildings. Build. Environ., 43(4), 537-549.

[58] Hong Kong Observatory, Summary of Meteorological and Tidal Observations in Hong Kong in 2015 (2016).

[59] King's Park Meteorological Station <http://www.hko.gov.hk/wxinfo/aws/kpinfo.htm>, 19 December 2012 (accessed on 4 March 2017).

[60] Climate Normals of Hong Kong (1981-2010). <http://www.hko.gov.hk/cis/normal/1981_2010/normals _e. htm\#table4>, 23 Mar 2015, (accessed on13 January.2017)

[61] Penwarden A. D. (1973). Acceptable wind speeds in towns. Building Science, 8(3), 259-267.

[62] ASCE, American Society of Civil Engineers (ASCE) manuals and reports on engineering practice No. 67: wind tunnel studies of buildings and structures. Viginia, (1999).

[63] A.W.E.S. (AWES), Assurance Manual for Wind-Engineering Studies of Buildings (AWES-QAM-1), 2001. [64] Verkaik J. W. (2000). Evaluation of two gustiness models for exposure correction calculations. J. Appl. Meteor., 39(9), 1613-1626.

[65] Verkaik J. W. (2006). On wind and roughness over land [M].

[66] WMO, Guidelines on Multi-hazard Impact-based Forecast and Warning Services, WMO-No. 1150 (2015)

34pp. 